62

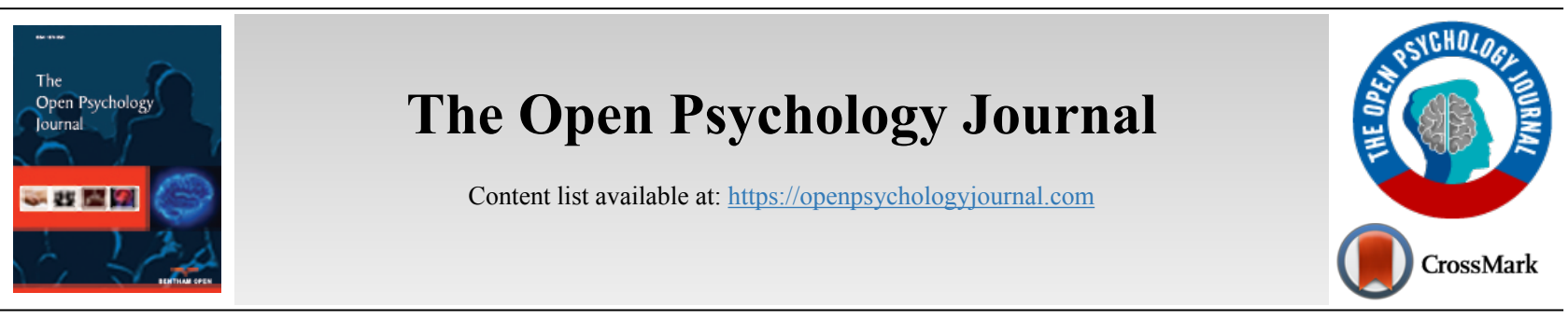

RESEARCH ARTICLE

\title{
Socio-Demographic and Environmental Determinants of Adverse Childhood Experience among School-Going Adolescents in Jimma town, Jimma, Southwest Ethiopia
}

\author{
Mekonnen Tsehay ${ }^{1, *}$, Mogesie Necho ${ }^{1}$, Asmare Belete $^{1}$ and Zelalem Belayneh ${ }^{2}$ \\ ${ }^{I}$ Department of Psychiatry, College of Medicine and Health Science, Wollo University, Dessie, Ethiopia \\ ${ }^{2}$ Department of Psychiatry, College of Medicine and Health Science, Dilla University, Dilla, Ethiopia
}

\begin{abstract}
:
Introduction:

Adverse childhood experience in adolescents is a global public health concern. Several risk factors have been identified so far across different parts of the world. However, there is a paucity of data in Ethiopia.

Objective:

To determine the prevalence and associated factors of Adverse Childhood Experience among school-going adolescents retrospectively.

Methods:

A cross-sectional school-based study was employed. Participants were selected using a multistage sampling technique. Adverse Childhood Experience Questionnaire Scale for childhood maltreatment. Multiple linear regressions were used to determine the association between Adverse Childhood Experience \& associated factors.

Results:

A total of 546 adolescents participated in the study with a response rate of $86 \%$. The mean $( \pm \mathrm{SD})$ age of participants was $16.83 \pm 1.26$ years. The majority (442 (81\%)) were studying in public schools and $104(19 \%)$ in private schools. Results show that $51.1 \%$ reported at least one, and respondents most often faced two ACEs (29.4\%), and as many as $10.4 \%$ reported at least four or more ACEs. According to the three categories of adverse childhood experience (ACE), from 329 female adolescents, 144(43.8\%) had been abused physically, verbally, or sexually, 65(17.8\%) had been neglected, and 169(51.1\%) had been household dysfunctional. And also, from 217 male adolescents, 93(42.9\%) had been abused physically, verbally, or sexually, $49(22 \%)$ had neglected, and $117(53.9 \%)$ had household dysfunction. Gender, social support, residence, educational status of parent, and having one or more chronic medical, mental, or neurological disorders were significantly associated with Adverse Childhood Experiences.

\section{Conclusion:}

Results of the study show that there was a significant prevalence of Adverse Childhood Experiences. Adverse Childhood Experiences have a tremendous impact on future health, well-being, and opportunity. Reduction and prevention of Adverse Childhood Experiences are mandatory for all children to reach their full potential. Those who are already exposed to Adverse Childhood Experiences also need social support, help them manage their experiences, and lead meaningful lives.
\end{abstract}

Keywords: Adverse childhood experience, Adolescents, Abuse, Household dysfunction, Neglect, Relationships.

\begin{tabular}{|l|l|l|l}
\hline Article History & Received: September 10, 2020 & Revised: December 3, 2020 & Accepted: January 23, 2021
\end{tabular}

\section{INTRODUCTION}

Adverse childhood experience refers to any act of abuse, household dysfunction, or neglectful behavior by a parent or caregiver that results in harm, the potential for harm, or threat

\footnotetext{
* Address correspondence to this author at the Department of Psychiatry, College of Medicine and Health Science, Wollo University, Po Box: 1145 Dessie, Ethiopia; E-mail: jimma1760@gmail.com
}

of harm to a child [1]. The different forms of adverse childhood experiences ranging from physical violence (hitting with the stick or other objects), emotional violence (threatening to spank), and child neglect have been consistently reported to be the main approaches to controlling children's misbehavior [2 4].

A report by the global initiative on the prevalence of 
violence against children showed about $90 \%$ in West and Central Africa, and $89 \%$ in East and North Africa [5, 6].

Currently, researchers are revealing that ACEs are the risk factor for the development of mental illness and poor quality of life. The study found that the risk for depression increased as a function of the number of types of childhood adversities, and this might be because of the cumulative effect [7 - 9].

Research conducted in the rural areas of southern Taiwan junior high schools reported that 374 (22.2\%) had experienced physical abuse in childhood and reported as childhood physical abuse significantly increased the risk of depression [10].

A study from the USA reported that ACE was the most important predictor of the life history of MDD and these predictors were more important across models than the number of types of ACE [7].

In Ethiopia, a study conducted among adolescent female high school students, which states that the prevalence of lifetime rape among adolescent female high school students was $11 \%$ [11], and another survey in south Ethiopia, among elementary school student's, which shows that $20.9 \%$ of students were physically abused, and (64.8\%) were psychologically abused [12]. It shows that there is a high prevalence of adversity even if the study didn't identify whether it is from the primary caregiver/guardian or other people.

A more recent study in Ethiopia among school-going adolescents shows that the severity of depression and ACE had a positive dose-response relationship [13].

There is a need to design and implement interventions that prevent children from adverse childhood experiences.

Considering it is a public health concern, and due to little attention, this study will fill gaps of literature about prevalence and associated socio-demographic and environmental factors among school-going adolescents in Ethiopia.

\section{METHODS}

\subsection{Study Area}

This study was conducted in Jimma town government and private secondary schools. The town has six public and eight private high school's 11,423 students had registered for grades $9,10,11$, and 12 in the academic year of 2017/18. Of these, 7241 were from public and 4182 were from private schools.

\subsubsection{Study Design and Period}

A school-based cross-sectional study design was employed from April - May 2018 G.C.

\subsubsection{Inclusion}

All adolescent students of Jimma town secondary school presented during the data collection period had been included.

\subsubsection{Exclusion Criteria}

Adolescents found to have severe illness during the study period, and difficulties in communication to the data collectors were excluded.

\subsection{Sample Size Determination and Sampling Techniques}

\subsubsection{Sample Size}

The sample was calculated by taking the proportion $50 \%$ and assuming any particular outcome with a 5\% margin of error and $95 \%$ confidence interval, 1.5 design effects, and 10\% non-responsive rate, using a single population proportion formula, the final sample size was 634 .

\subsubsection{Sampling Techniques}

A Multistage sampling technique was used, and a sampling scheme from government and private schools is shown in Fig. 1.

\subsubsection{Data Collection and Instruments}

A self-administered questionnaire was prepared in English then translated into Afaan Oromo and Amharic languages for better understanding. The data were collected by a pretested structured self-administered questionnaire, includes sociodemographic characteristics, substance use, social support, and ACE. Adverse Childhood Experience Questionnaire (ACE), which is a self-report instrument covering 10 items, to rate the type and severity of abuse, neglect, and household dysfunction [14].

\subsubsection{Statistical Analysis}

Before the data analyses were conducted, the normal distribution of continuous dependent variables was verified using the P-P-plot and K-S tests. Descriptive analyses were computed in terms of mean and standard deviation for continuous variables and frequency with a percentage for nominal variables. Multiple linear regression analysis was performed to examine the associations between independent variables and ACE. All analyses were conducted using SPSS for Windows, Version 23.0; Statistical significance was defined as $P<0.05$ (two-tailed).

\subsubsection{Ethical Considerations}

The study was conducted after ethical clearance was obtained from the Institutional Review Board (IRB) of Jimma University. One day before data collection selected adolescent students in the selected schools were provided a consent form paper to take to their parents/guardians at home to be signed by parents or guardians. Participants were also given written informed assent and signed for their participation.

\section{RESULTS}

\subsection{Description of Socio-demographics}

Among the total number of 634 distributed questionnaires, 546 were filled completely and consistently, making a response rate of $86.12 \%$. The remaining 88 questionnaires were not included in the study as a result of non-response rates collected from all the sampled schools. Of these, 442 (81\%) were studying in public schools and 104 (19\%) in private schools. The mean age of the participants was 16.83 years $(\mathrm{SD} \pm 1.26)$ (Table 1). 


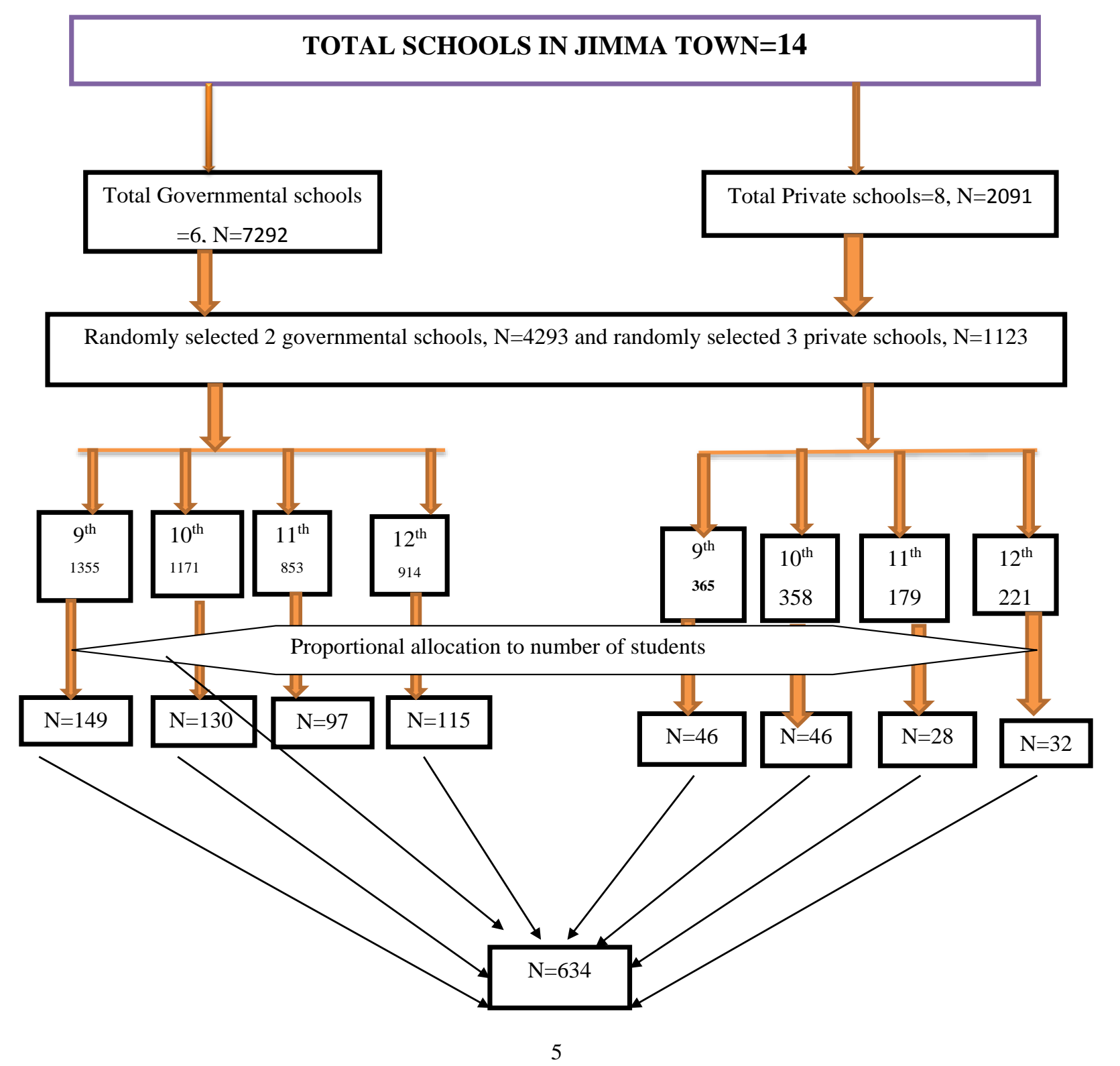

Fig (1). Schematic representation of study sample.

Table 1. Socio-Demographic profile of adolescents who participated in the study $(n=546)$.

\begin{tabular}{|c|c|c|c|}
\hline Variable & Type of Variable & Frequency & Percent (\%) \\
\hline \multirow{4}{*}{ Age } & 14 & 13 & 2.4 \\
\cline { 2 - 4 } & 15 & 84 & 15.4 \\
\cline { 2 - 4 } & 16 & 114 & 20.9 \\
\cline { 2 - 4 } & 17 & 153 & 28.0 \\
\cline { 2 - 4 } & 18 & 137 & 25.1 \\
\cline { 2 - 4 } & 19 & 45 & 6.2 \\
\hline \multirow{3}{*}{ Sex } & Female & 329 & 39.3 \\
\cline { 2 - 4 } & Male & 217 & 39.7 \\
\hline
\end{tabular}




\begin{tabular}{|c|c|c|c|}
\hline Variable & Type of Variable & Frequency & Percent (\%) \\
\hline \multirow{4}{*}{ Grade } & 9 & 174 & 31.9 \\
\hline & 10 & 153 & 28.0 \\
\hline & 11 & 103 & 18.9 \\
\hline & 12 & 116 & 21.2 \\
\hline \multirow{4}{*}{ Religion } & Orthodox Christian & 212 & 38.8 \\
\hline & Muslim & 240 & 44.0 \\
\hline & Protestant & 75 & 13.7 \\
\hline & Others & 19 & 3.5 \\
\hline \multirow{2}{*}{ School } & Governmental & 442 & 81.0 \\
\hline & Private & 104 & 19.0 \\
\hline \multirow{4}{*}{ Occupation of father } & Laborer & 40 & 7.3 \\
\hline & Merchant & 219 & 40.1 \\
\hline & Private & 124 & 22.7 \\
\hline & Governmental & 163 & 29.9 \\
\hline \multirow{5}{*}{ Occupation of mother } & Laborer & 34 & 6.2 \\
\hline & Merchant & 93 & 17.0 \\
\hline & Private & 137 & 25.1 \\
\hline & Government & 147 & 26.9 \\
\hline & House wife & 135 & 24.7 \\
\hline \multirow{5}{*}{ Educational status of father } & Illiterate & 40 & 7.3 \\
\hline & $1-4$ & 69 & 12.6 \\
\hline & $5-8$ & 124 & 22.7 \\
\hline & $9-12$ & 163 & 29.9 \\
\hline & Certificate and above & 150 & 27.5 \\
\hline \multirow{5}{*}{ Educational status of mother } & Illiterate & 51 & 9.3 \\
\hline & $1-4$ & 96 & 17.6 \\
\hline & $5-8$ & 159 & 29.1 \\
\hline & $9-12$ & 138 & 25.3 \\
\hline & Certificate and above & 102 & 18.7 \\
\hline \multirow{2}{*}{ Adolescents residence } & Urban & 450 & 82.4 \\
\hline & Rural & 96 & 17.6 \\
\hline \multirow{4}{*}{ Ubstance use among adolescents } & Cigarette smokers & 5 & .9 \\
\hline & Alcohol drinkers & 90 & 16.5 \\
\hline & Khat chewers & 44 & 8.1 \\
\hline & Other illegal drugs & 5 & .9 \\
\hline
\end{tabular}

Note: Other illegal drugs include Ganja, Shisha, and Other substances or medication use.

\subsection{Adverse Childhood Experience among Adolescents}

The adverse childhood experience questionnaire tool was used to assess retrospectively ACE among adolescents having 3 hallmarks, mainly known as abuse which asks about physical, emotional, and sexual questions. Where the neglected part assesses physical and emotional neglect, and the household dysfunction section involves the questions about divorce, mother treats violently, substance abuse, mental illness, and incarcerated relative. Of all participants, 51.1\% reported at least one, and $29.4 \%$ of respondents faced two ACEs and as many as $10.4 \%$ reported at least four or more ACEs (Table 2). According to the three categories (abuse, neglect, and household dysfunction) of ACE, 144(43.8\%) of female adolescent students had abused physically, verbally, or sexually, 65(17.8\%) female adolescent students had neglected and $169(51.1 \%)$ female adolescent students had household dysfunction. And 93(42.9\%) of male adolescent students had abused physically, verbally, or sexually, 49(22\%) male adolescent students had neglected and 117(53.9\%) male adolescent students had household dysfunction.

The overall differences in ACE prevalence rates (ACE score one or more) between males and females were statistically significant, using independent samples tests, a $p$ value less than .002 , with females having a higher prevalence rate of each ACE for the overall ACE score.

\subsection{Social Support}

Measurement by the Oslo Three Items Social Support Scale revealed that $173(31.7 \%)$ of respondents received poor social support, $211(38.6 \%)$ of them had moderate social support, while $162(29.7 \%)$ had strong social support.

\subsection{Substance use among Adolescents}

This study shows that the significant number of students use alcohol at $16.1 \%$, followed by khat chewing behavior at $8.1 \%$, and the small number of students who use cigarette smoking and other illicit drug users at $0.9 \%$ each. 
Table 2. Prevalence of adverse childhood experience among adolescents.

\begin{tabular}{|c|c|c|c|c|c|c|c|}
\hline \multicolumn{2}{|c|}{ ACE category } & \multicolumn{2}{|c|}{ Male (217) } & \multicolumn{2}{|c|}{ Female (329) } & \multicolumn{2}{|c|}{ Total(546) } \\
\hline & & Frequency & Percent & Frequency & Percent & Frequency & Percent \\
\hline \multirow[t]{5}{*}{ Household dysfunction } & Household substance abuse & 31 & 14.3 & 25 & 7.6 & 56 & 10.3 \\
\hline & Household member mentally ill & 16 & 7.4 & 16 & 4.9 & 32 & 5.9 \\
\hline & Parental separation/divorce & 31 & 14.3 & 60 & 18.2 & 91 & 16.7 \\
\hline & Incarcerated household member & 26 & 12.0 & 50 & 15.2 & 76 & 13.9 \\
\hline & Family Violence & 13 & 6.0 & 18 & 5.5 & 31 & 5.7 \\
\hline \multirow[t]{3}{*}{ Abuse } & Emotional Abuse & 52 & 24.0 & 62 & 18.8 & 432 & 79.1 \\
\hline & Physical Abuse & 35 & 16.1 & 51 & 15.5 & 86 & 15.8 \\
\hline & Sexual Abuse & 6 & 2.6 & 31 & 9.5 & 37 & 6.8 \\
\hline \multirow[t]{2}{*}{ Neglect } & Emotional Neglect & 26 & 12.0 & 41 & 12.5 & 67 & 12.3 \\
\hline & Physical Neglect & 23 & 10.6 & 24 & 7.3 & 47 & 8.6 \\
\hline \multirow[t]{5}{*}{ ACE Score } & 0 & 99 & 45.6 & 168 & 51.1 & 267 & 48.9 \\
\hline & 1 & 51 & 23.5 & 67 & 20.4 & 118 & 21.6 \\
\hline & 2 & 29 & 13.4 & 47 & 14.3 & 76 & 13.9 \\
\hline & 3 & 10 & 4.6 & 18 & 5.5 & 28 & 5.1 \\
\hline & $\geq 4$ & 28 & 12.9 & 29 & 8.8 & 57 & 10.4 \\
\hline
\end{tabular}

\subsection{Regression Analysis}

Simple/bivariate and multiple linear analyses were performed to identify the association of ACE with sociodemographic factors. All variables that show $p$-value $\leq 0.25$ in simple linear regression were entered into multiple regressions to control for potential confounders.

\subsection{Independent Predictors of ACEs among Adolescents}

In the final model, among many variables included in the multiple linear regression analysis, only gender, social support, residence, educational status of parent, and having one or more chronic medical, mental, or neurological disorders were significantly associated with ACEs. Of this male sex, social support, educational status of parent certificate and above, and urban residence were negatively associated, and others were positively associated with ACEs.

As shown in Table 2, being male decreases ACE score by 0.527 units $(\beta=-0.527,95 \% \mathrm{CI}(-0.948,-0.034)$ as compared to females and coming from rural Woredas of Jimma zone increases ACE score by 1.235 ( $\beta=1.235,95 \% \mathrm{CI}(0.673,2.332)$.

A unit change in the oslo-3 social support scale score also decreases the ACE score by $0.616(\beta=-0.616,95 \% \mathrm{CI}(-0.833$, -0.499). from parental-related factors having a certificate and above by educational level in both mothers and fathers decrease the ACE score $(\beta=-0.596,95 \%$ CI $(-1.506,-0.009)$. $(\beta=-0.748,95 \% \mathrm{CI}(-1.506,-0.009)$ respectively.

\section{DISCUSSION}

Childhood maltreatment is a common problem that plays an important role in shaping risk for physical, mental health problems across the lifespan. In line with previous studies, our findings indicate from all participants, $51.1 \%$ reported at least one, and $29.4 \%$ of respondents faced two ACEs, and as many as $10.4 \%$ reported at least four or more ACEs $[15,16]$. Lower than the study was done in Iran and Belgravia the difference might be due to the tool they used is different from the current study and the study population culture to report adversity $[17$, 18].

Childhood adversities in the current study include experiences involving emotional abuse $(24 \%$, and $18.8 \%$ in males and females respectively) to the adolescent and experiences that involve parental separation/divorce (14.3\%, and $18.2 \%$ in males and females respectively).

These types of adverse experiences are common in many countries $[3,19]$. We also found physical abuse in males is $16 \%$, in females $15.5 \%$, which lower than the study was done in Arbaminch, Southern Ethiopia, they only studied physical abuse and tool adapted from literature [20]. And also current finding was much lower than another previous study, which might be population difference $[3,17,18]$.

Female sexual abuse $(9.5 \%)$ was found to more prevalent than male $(2.6 \%)$, which is in line with other previous studies done in Minnesota [2]. But still, it is much lower than the study done in Iran [17].

Similar to previous studies $[15,17]$, the relationship between parents' education status and prevalence of ACE was significant. As shown in the Table $\mathbf{3}$, having a certificate and above by educational level in both mothers and fathers decrease ACE score $((\beta=-0.596,95 \% \mathrm{CI}(-1.506,-0.009))$. $(\beta=-$ $0.748,95 \%$ CI $(-1.506,-0.009)$, respectively.

Furthermore, having good social support decreases ACE score (A unit change in Oslo-3 social support scale score also decreases ACE score by $0.616(\beta=-0.616,95 \%$ CI $(-0.833$, $-0.499)$. This was in line with the previous finding that, Social support might have a protective or buffering effect against the consequences of a stressful event by enhancing cognitive and emotional processing of the experience [21]. 
Table 3. Final multivariate regression model for ACEs among adolescents in the sampled secondary schools in Jimma town, Ethiopia, (n=546).

\begin{tabular}{|c|c|c|c|c|c|}
\hline \multirow[b]{2}{*}{ Explanatory variable } & \multirow[b]{2}{*}{ Variable Type } & \multirow{2}{*}{$\begin{array}{c}\text { Unstandardized } \\
\text { Coefficients } \\
\text { b }\end{array}$} & \multirow[b]{2}{*}{$p$-value at $95 \%$ CI } & \multicolumn{2}{|c|}{ 95.0\% Confidence Interval for $b$} \\
\hline & & & & Lower Bound & Upper Bound \\
\hline \multirow[t]{2}{*}{ Sex } & female* & 0 & & & \\
\hline & male & -0.527 & 0.002 & -0.948 & -0.034 \\
\hline \multirow{4}{*}{$\begin{array}{l}\text { Grade level } \\
\text { students }\end{array}$} & grade 9 & 0 & & & \\
\hline & grade 10 & 0.429 & 0.020 & -0.124 & 1.830 \\
\hline & grade 11 & -0.015 & 0.173 & -0.882 & 1.853 \\
\hline & grade 12 & 0.350 & 0.210 & -0.124 & 1.775 \\
\hline \multirow[t]{2}{*}{ School type } & private* & 0 & & & \\
\hline & governmental & -0.546 & 0.014 & -0.937 & -0.209 \\
\hline \multirow[t]{2}{*}{ Residence } & urban* & 0 & & & \\
\hline & rural & 1.235 & 0.001 & 0.673 & 2.332 \\
\hline \multirow[t]{4}{*}{ Educational Status of the Father } & illiterate* & 0 & & & \\
\hline & primary & 1.022 & 0.005 & 0.318 & 1.727 \\
\hline & secondary & -0.353 & 0.039 & -1.094 & -0.1880 \\
\hline & certificate and above & -0.748 & 0.053 & -1.506 & -0.009 \\
\hline \multirow[t]{4}{*}{ Educational status of the Mother } & illiterate* & 0 & & & \\
\hline & primary & 0.330 & 0.341 & -0.350 & 1.010 \\
\hline & secondary & 0.066 & 0.867 & -0.714 & 0.847 \\
\hline & certificate and above & -0.596 & 0.048 & -1.465 & -0.273 \\
\hline \multicolumn{2}{|c|}{ having a chronic medical or mental illness } & 2.856 & 0.001 & 1.219 & 4.494 \\
\hline \multicolumn{2}{|c|}{ Oslo 3 social support category } & -0.616 & 0.001 & -0.833 & -0.499 \\
\hline
\end{tabular}

NOTE:-*reference group,

\subsection{Strength and Limitation of the Study}

This study, to our knowledge, provides the prevalence estimates of ACE and the association of socio-demographic factors among a sample of school going-adolescents in Ethiopia. The major strength of this study was the random selection of the schools and adolescents. We also use standardized, reliable, and valid data collection tools and incorporate several variables to reduce the confounding effect. Also, our study is unique in using continuous scores for ACE instead of using a cut-off point. This is an advantage because continuous scores are more likely to reflect reality compared with using a cut-off point. However, our study has certain limitations, this study will only give clues whether certain factors may or may not be potential etiological factors of ACE symptoms in school-going adolescents in Jimma town. Therefore, studies with better epidemiological design such as the case-control study can be used to investigate the risk factors for depression in school-going adolescents.

\section{CONCLUSION}

In conclusion, this study provided information regarding the magnitude of ACE and many modifiable risk factors for ACE among school-going adolescents. Interventions aimed at the prevention of ACE require changing community perceptions and responses, The first step toward the prevention of ACE is an understanding of the prevalence and factors associated with ACE, so our research will be used as a baseline for those who want to do further research and intervention.

\section{AUTHORS' CONTRIBUTIONS}

Mekonnen Tsehay conceived and designed the study. Mekonnen Tsehay, Mogesie Necho, Asmare belete, and Zelalem Belayneh analyzed the data and drafted the manuscript. All the authors read the manuscript several times and have given their final approval for publication.

\section{ETHICS APPROVAL AND CONSENT TO PARTI- CIPATE}

This study was approved by the Institutional Review Board (IRB) of Jimma University, Ethiopia under approval no. (Ref. $\mathrm{No}=\mathrm{JHRPGD} / 334 / 18)$.

\section{HUMAN AND ANIMAL RIGHTS}

No Animals were used in this research. All human research procedures followed were in accordance with the ethical standards of the committee responsible for human experimentation (institutional and national), and with the Helsinki Declaration of 1975, as revised in 2013.

\section{CONSENT FOR PUBLICATION}

Written informed consent and assent was obtained from each participant.

\section{AVAILABILITY OF DATA AND MATERIALS}

The data and materials used to support the findings of this study are available from the corresponding author [M.T] upon reasonable request. 


\section{FUNDING}

This research was supported by Wollo University, Ethiopia under grant number WU 12583/n-05/18.

\section{CONFLICT OF INTEREST}

The authors declare no conflict of interest, financial or otherwise.

\section{ACKNOWLEDGEMENTS}

We would like to thank Jimma zone school administrators and students who gave us support and information. We also would like to thank MSC students of ICCMH for their genuine help, especially during the data collection and data entry of the study.

\section{REFERENCES}

[1] Nemeroff CB. Paradise lost: The neurobiological and clinical consequences of child abuse and neglect. Neuron 2016; 89(5): 892-909.

[http://dx.doi.org/10.1016/j.neuron.2016.01.019] [PMID: 26938439]

[2] Saewyc EM, Pettingell S, Lara L. Prevalence of sexual abuse among adolescents in school 2003; 19(5): 266-72.

[3] Chiu GR, Lutfey KE, Litman HJ, Link CL, Hall SA, McKinlay JB. Prevalence and overlap of childhood and adult physical, sexual, and emotional abuse: A descriptive analysis of results from the Boston Area Community Health (BACH) survey. Violence Vict 2013; 28(3): 381-402.

[http://dx.doi.org/10.1891/0886-6708.11-043] [PMID: 23862305]

[4] Haile RT, Kebeta ND, Kassie GM. Prevalence of sexual abuse of male high school students in Addis Ababa, Ethiopia. BMC Int Health Hum Rights 2013; 13(1): 24

[http://dx.doi.org/10.1186/1472-698X-13-24] [PMID: 23680171]

[5] Global Initiative to End All Corporal Punishment of Children. Corporal punishment and children's right to health. END GLOBA. L Punishm 2012; 4(13): 1-5.

[6] Human N, Action R. Information from tanzania albinism society. CHRAGG Investig 2017; 34(12-32): 1-5.

[7] Khan A, McCormack HC, Bolger EA, et al. Childhood maltreatment, depression, and suicidal ideation : Critical importance of parental and peer emotional abuse during developmental sensitive periods in males and females. Front Psychiatry 2015; 6(March): 42. [http://dx.doi.org/10.3389/fpsyt.2015.00042] [PMID: 25870565]

[8] Van Duin L, Bevaart F, Zijlmans J, et al. The role of adverse childhood experiences and mental health care use in psychological dysfunction of male multi - problem young adults. Eur Child Adolesc Psychiatry 2018.

[http://dx.doi.org/10.1007/s00787-018-1263-4] [PMID: 30552585]
[9] Felitti VJ, Anda RF. The relationship of adverse childhood experiences to adult health status the Adverse Childhood Experiences (ACE) study. Perm J 2002; Winter. 6(1): 44-7.

[10] Yen CF, Yang MS, Chen CC, et al. Effects of childhood physical abuse on depression, problem drinking and perceived poor health status in adolescents living in rural Taiwan. Psychiatry Clin Neurosci 2008; 62(5): 575-83.

[http://dx.doi.org/10.1111/j.1440-1819.2008.01836.x] [PMID: 18950378]

[11] Mekuria A, Nigussie A, Abera M. Childhood sexual abuse experiences and its associated factors among adolescent female high school students in Arbaminch town, Gammo Goffa zone, Southern Ethiopia: a mixed method study. BMC Int Health Hum Rights 2015; 15: 21. [http://dx.doi.org/10.1186/s12914-015-0059-6] [PMID: 26283662]

[12] Mulatie M. Psychology \&amp; Psychotherapy Physical and Psychological Child Abuse in Ethiopia: Cit Mulatie M. J Psychol Psychother 2014; 4(2): 2-7. [http://dx.doi.org/10.4172/2161-0487.1000137]

[13] Tsehay M, Necho M, Mekonnen W. The role of adverse childhood experience on depression symptom, prevalence, and severity among school going adolescents. Depress Res Treat 2020; 20205951792 [http://dx.doi.org/10.1155/2020/5951792] [PMID: 32257437]

[14] Kazeem OT. A Validation of the Adverse Childhood Experiences Scale in Nigeria. Res Humanit Soc Sci 2015; 5(11): 2225-484.

[15] Blum RW, Li M, Naranjo-Rivera G. Measuring adverse child experiences among young adolescents globally: Relationships with depressive symptoms and violence perpetration. J Adolesc Health 2019; 65(1): 86-93.

[http://dx.doi.org/10.1016/j.jadohealth.2019.01.020] [PMID: 30930089]

[16] Lu W. Adverse childhood experiences and adolescent mental disorders : protective mechanisms of family functioning, social capital , and civic engagement adverse childhood experiences and adolescent mental disorders : Protective mechanisms of family functioning. Heal Behav Res 2019; 2(1)

[17] Pirdehghan A, Vakili M, Rajabzadeh Y, Puyandehpour M. Child abuse and neglect epidemiology in secondary school students of Yazd province, Iran. Iran J Psychiatry Behav Sci 2015; 9(4)e2256 [http://dx.doi.org/10.17795/ijpbs-2256] [PMID: 26834803]

[18] Raddi SA. Salimath GB. International Journal of Scientific Research and Reviews 2019; 0-11.

[19] Sørbø MF, Grimstad H, Bjørngaard JH, Schei B, Lukasse M. Prevalence of sexual, physical and emotional abuse in the Norwegian mother and child cohort study. 2013.

[20] Unasho YS, Mekuria MS, Gube AA. Prevalence and Contributing Factors of Childhood Physical Abuse in Households and at Schools among School Adolescents in Arba Minch Town, Southern Ethiopia. J Child Adolesc Behav 2017; 05(01): 1-5.

[http://dx.doi.org/10.4172/2375-4494.1000331]

[21] Brinker J, Cheruvu VK. Social and emotional support as a protective factor against current depression among individuals with adverse childhood experiences. Prev Med Rep 2016; 5(5): 127-33. [http://dx.doi.org/10.1016/j.pmedr.2016.11.018] [PMID: 27981026]

(C) 2021 Tsehay et al.

This is an open access article distributed under the terms of the Creative Commons Attribution 4.0 International Public License (CC-BY 4.0), a copy of which is available at: https://creativecommons.org/licenses/by/4.0/legalcode. This license permits unrestricted use, distribution, and reproduction in any medium, provided the original author and source are credited. 